\title{
Hyperkalaemia: a dangerous electrolyte disturbance
}

M elanie H umphreys, M A, BSc (H on), EN B 124, R GN , O N C, Senior Lecturer, University of Wolverhampton, Wolverhampton, UK.

M elanie H umphreys, M A, BSc (H on), EN B 124, R GN , O N C, Senior Lecturer, Post-registration Studies, School of H ealth, N ew Cross Centre, University of Wolverhampton, Wolverhampton, WV10 0QP, UK. e-mail: in5277@wlv.ac.uk

\section{INTRODUCTION}

The most important electrolytes are sodium, potassium, calcium and magnesium. The flow of these electrolytes into and out of cardiac cells, as currents, creates the energy needed for depolarisation and repolarisation and allows contractile mechanisms to function. The levels of electrolytes in the fluid bathing the cardiac cells has an effect on these currents and the appearance of the complexes seen on the electrocardiograph (ECG).

Of all the electrolyte changes that can occur, hyperkalaemia is the most dangerous. H yperkalaemia can not only kill, but it can kill in minutes, or even seconds, and it prevents response to the drugs used in resuscitation (Garcia \& Holtz, 2001). $H$ yperkalaemia causes changes in the appearance of the ECG, symbolising the changes in cell function, and can cause any and all arrhythmias. Immediate recognition and action to stabilise the myocardial membrane and reverse the pathological processes are the keys to combatting effectively the complications of hyperkalaemia (Garcia \& Holtz, 2001). The nurse within the critical care area is in the optimum position to diagnose and direct such management.

\section{PATHOPHYSIOLOGY}

$\mathrm{H}$ yperkalaemia refers to an increased serum potassium concentration and is said to exist when the potassium $\left(\mathrm{K}^{+}\right)$level is above $5 \mathrm{mmol} / \mathrm{l}$. The normal range for potassium is 3.8-5 $\mathrm{mmol} / \mathrm{l}$ (Tortora \& A nagnostakos, 2000). For the cardiac patient, a serum level of at least $4.0 \mathrm{mmol} / \mathrm{l}$ should be aimed for (Connaughton, 2001).There is a clear relationship between hypokalaemia and the frequency of ventricular fibrillation (VF) in acute myocardial infarction (N ordrenhaug \& von der Lippe, 1983).

H yperkalaemia has important and potentially serious effects on cardiac function. When the serum potassium concentration increases, there is an increase in the ratio of extracellular to intracellular potassium concentrations. This influences depolarisation by lowering the resting membrane potential, so that cardiac cells become partially depolarised. Initially, this increases their excitability because the resting potential is close to the threshold potential. However, as the extracellular potassium concentration increases, the cardiac cells depolarise to the extent that they cannot repolarise. Cells in this state are non- excitable, meaning that no further contractile activity occurs.

As the serum potassium level increases further [Author: Correct as edited?], the rate of rise and amplitude of the action potential decreases and slows the cell-to-cell conduction velocity. $\mathrm{H}$ yperkalaemia reduces conduction velocity at all levels of the conduction system, including atrial, atrioventricular nodal, and intraventricular levels. In severe hyperkalaemia, intraventricular conduction may be completely inhibited. Bundle-branch block or, less frequently, complete heart block may occur (Smith and Kampine, 1990; Woods et al., 1995).

$\mathrm{H}$ yperkalaemia is caused by increased potassium intake; a shift in potassium ions from the cells to the extracellular fluid; decreased potassium excretion; or any combination of these factors (Flever, 1991). [AUTH O R: Reference missing from final list.] Table 1 lists some examples of specific aetiological factors in each of these categories.

$\mathrm{H}$ yperkalaemia occurs across a spectrum of presentation, both in actual blood levels and in the ECG representation of the pathology. [Author: Correct as edited?] There may be a poor correlation between serum potassium and the typical ECG changes (Wagner, 1994). However, $T$ wave changes are constantly reported as the earliest sign of hyperkalaemia and are typically noted in V 2 to V 4 in the first instance (Garcia \& H oltz, 2001). ECG changes can be apparent when the $K^{+}$exceeds 5.5 $\mathrm{mmol} / \mathrm{l}$.

\section{ECG IDENTIFICATION}

Although ECG changes reportedly take place along a spectrum, these changes are more apparent with severe hyperkalaemia (>8 $\mathrm{mmol} / \mathrm{l})$. H owever, these changes are not reliably correlated with the pathology involved [Author: Correct as edited?] (Szerlip et al., 1986). The characteristic ECG changes of hyperkalaemia are:

- T wave abnormalities, especially tall and peaked (tented) with a narrow base and symmetrical shape - in any combination

_ Intraventricular conduction delays, leading to widening of the Q RS complex [Author: Correct as edited?]

ST segment changes simulating an injury pattern (typically depression, although elevation may occur)

$\mathrm{P}$ waves decreased amplitude and prolongation (maybe missing at higher $\mathrm{K}+$ levels) 
PR interval prolongation

- Cardiac arrhythmias, any and all varieties! A sine-wave pattern appears in severe, often terminal, hyperkalaemia.

\begin{tabular}{|c|c|}
\hline Types of aetiology & Examples \\
\hline Increased potassium intake & $\begin{array}{l}\text { Excessive intravenous } \\
\text { administration of } \mathrm{K}^{+} \\
\text {Massive transfusion (>10 units) of } \\
\text { blood stored longer than } 3 \text { days ( } \mathrm{K}^{+} \\
\text {ions leave the red blood cells) } \\
\text { Large oral intake and reduced renal } \\
\text { excretion }\end{array}$ \\
\hline $\begin{array}{l}\text { Movement of potassium } \\
\text { out of cells }\end{array}$ & $\begin{array}{l}\text { Acidosis (e.g. diabetic } \\
\text { ketoacidosis, lactic acidosis) } \\
\text { Insulin deficiency } \\
\text { Massive cell death (crushing } \\
\text { injuries, burns, cytotoxic drugs) } \\
\text { Large overdose of digitalis }\end{array}$ \\
\hline $\begin{array}{l}\text { Decreased potassium } \\
\text { excretion }\end{array}$ & $\begin{array}{l}\text { Oiguria } \\
\text { Extra cellular volume depletion } \\
\text { Renal failure } \\
\text { Decreased aldosterone } \\
\text { Addison disease } \\
\text { Chronic heparin administration } \\
\text { Lead poisoning } \\
\text { Angiotensin-converting enzyme } \\
\text { inhibitors (ACE) } \\
\text { Other } \\
\text { Potassium-sparing diuretics } \\
\text { (spironolactone, amiloride) }\end{array}$ \\
\hline
\end{tabular}

The patient is typically haemodynamically stable and the sequence of ECG changes can be extremely rapid with catastrophic consequences (W eizenberg et al., 1985; Rastergar \& Soleimani, 2001; Wagner, 1994; M etcalfe \& Seidelin, 1994; Jenkins \& Gerrard, 1999).

\section{MANAGEMENT}

When hyperkalaemia of more than $6 \mathrm{mmol} / \mathrm{l}$ is present, lifethreatening cardiac arrhythmias may occur. An intravenous infusion of calcium chloride or calcium gluconate is used as a short-term measure to restore the membrane potential to a more stable state. Calcium promotes the entry of potassium ions from the intravascular to the intracellular compartment. In hyperkalaemia, this helps to reduce the serum potassium to safer levels (Prosser et al., 2000).

Insulin facilitates the transport of potassium as well as glucose into the cells, and so intravenous insulin, within an infusion of glucose to prevent hypoglycaemia, may be given; the serum potassium and glucose levels must be closely monitored (W illiams et al., 1988).

As a temporary measure, the production of alkalosis by the administration of sodium bicarbonate also produces a shift of potassium into the cells; however, this is only a short-term measure as sodium overload will exacerbate water retention. In addition, rapid alteration of the blood $\mathrm{pH}$ can cause disequilibration with the $\mathrm{pH}$ of the central nervous system tissue fluid.

There is evidence that pacemakers will not initiate 'capture' on the hyperkalaemic patient (Garcia \& Holtz, 2001; H umphreys, 2001).

\section{BOX 1}

Undertake a systematic analysis of the following 12-lead ECG.

RHYTHM STRIP: $25 \mathrm{~mm} / \mathrm{sec}: 1 \mathrm{~cm} / \mathrm{mV}$

\section{COMMENTARY}

The 12-lead ECG shows the following features:

$\sum$ H eart rate: $85 \mathrm{bpm}$

$\sum$ Rhythm: regular pattern, sinus rhythm

$\sum P$ waves: normal

$\sum$ PR interval: normal, 0.16 seconds

$\sum$ QRS complex: rS in V 1; qR in V6 - normal; rapid and early R wave progression, early transition zone V 2-V3; voltage less in V 6 than in V 5 - normal variant; R wave voltage measured in V $5=30 \mathrm{~mm}$ (just exceeding normal parameter of $27 \mathrm{~mm}$ )

$\sum$ QRS duration: 0.08 seconds

$\sum$ QT interval: 0.36 seconds

$\sum$ T wave: tall, peaked and narrow in V2-V 4. III and aVF greater than two-thirds of the height of the R wave (abnormal).

The diagnosis is sinus rhythm with $\mathrm{T}$ wave changes that are suggestive of hyperkalaemia. In this particular patient, the serum potassium was $6.4 \mathrm{mmol} / \mathrm{l}$. T wave changes do not need to be apparent in all leads - as evidenced here. The selective lead changes apparent on this ECG may be accounted for by their closer proximity to the heart. 
BOX 2

[Consider the following single-lead ECG recording

[SIN GLE LEAD ECG HERE]

Lead II

ECG broad complex rhythm - sine wave pattern

\section{COMMENTARY}

Pulse rate: 100 bpm

- Puulse rhythm: regular

- QRS complex: broad and bizarre; 0.28 seconds. This would suggest ventricular tachycardia (VT) or intraventricular conduction delay (IVCD). Some individual complexes can be determined. However, they may merge into one another as time continues.

_ P waves: some notches apparent before QRS complexes (which would favour diagnosis of IV CD rather than VT)

- T waves: unable to discern.

If this patient has progressed into this rhythm, treat immediately for hyperkalaemia. The next most likely rhythm will be asystole! An arterial blood gas with potassium level will give a rapid preliminary answer. For the unknown patient who presents in this pattern, it is appropriate to treat as VT and hyperkalaemia simultaneously (R esuscitation Council, 2000).

This particular recording was taken from a patient with chronic renal failure. The serum potassium was $9.6 \mathrm{mmol} / \mathrm{l}$ and an injection of calcium gluconate led to a return of a P wave, nar rowing of the Q R S complex, return of an ST segment and a T wave more typical of hyperkalaemia.

\section{CONCLUSION}

$\mathrm{H}$ yperkalaemia is readily recognised from a 12-lead ECG recording, with the earliest features being $T$ wave changes. $T$ wave changes may be altered as a result of the intraventricular conduction delay that develops with severe hyperkalaemia and can be confused with haemodynamically stable ventricular tachycardia. With hyperkalaemia, there are only seconds to minutes to intervene before possible life-threatening arrhythmias may develop (Garcia and Holtz, 2001). Thus, early recognition and intervention are vital for patient welfare. This article has review ed the pathophysiological characteristics and the essential management in an attempt to promote insightful, individualistic care within the critical care area.

\section{RERERECS}

Connaughton M. (2001). Evidence-Based Coronary Care. London: Churchill Livingstone.

Flever, 1991. [A uthor. Please complete reference.]

Garcia TB, Holtz NE. (2001). 12-lead ECG:The Art of Interpretation. London: Jones and Bartlett.

H umphreys M. (2001). Atrioventricular block (heart block) of the third degree. Connect; 1: 120-123.

Jenkins RD, Gerred SJ. (1999). ECGs by Example. London: Churchill Livingstone.

Lilly LS. (1993). Pathophysiology of $\mathrm{H}$ eart Disease: A Collaborative Project of $M$ edical Students and Faculty. London: Lea and Febiger.

M etcalfe M J, Seidelin PH. (1994). Images in cardiology. ECG changes of severe hyperkalaemia. British $\mathrm{H}$ eart Journal ; 72: 260

Nordrehaug JE, Von Der Lippe G. (1983). Hypokalaemia and ventricular fibrillation in actue myocardial infarction. British H eart J ournal; 50: 525-529.

Prosser S, Worster B, M acgregor J, Dewar K. (2000). Applied Pharmacology. London: M osby.

Rastergar A, Soleimani M (2001). H ypokalaemia and hyperkalaemia. Postgraduate M edical J ournal; 77: 759-764.

Resusciation Council (UK). (2000). Advanced Life Support Course Provider $M$ anual (4th ed.) London: Resusciation council (UK) and European Resuscitation Council.

Smith JJ, Kampine JP. (1990). Circulatory Physiology - the Essentials. (3rd edn.) London: Williams and Wilkins.
Szerlip HM, Weiss J, Singer I. (1986). Profound hyperkalaemia without electrocardiographic manifestations. American Journal of Kidney Disease; 7 : 461-465.

Tortora GJ, Anagnostakos N P. (2000). Principles of Anatomy \& Physiology. (7th ed.) N ew Y ork: H arper Collins.

Wagner GS. (1994). M arriott's Practical Electrocardiography. (9th ed.) London: Williams and Wilkins.

Weizenberg A, Class RN, Surawicz B. (1985). Effects of hyperkalaemia on the electrocardiogram of patients receiving digitalis. American Journal of Cardiology; 55: 968-973.

Williams PS, Davenport A, Bone JM . (1988). H ypoglycaemia following treatment of hyperkalaemia with insulin and dextrose. Postgraduate M edical Journal; 64: 30-32.

Woods SL, Froelicher ESS, Halpenny CJ, Underhill-M otzer S. (1995). Cardiac $\mathrm{N}$ ursing. (3rd ed.) Pennsylvania: Lippincott. 